\title{
INSIGHTS OF GENDER BASED TOURISTS PREFERENCES BY CONSTRUCTING TRAVEL DIARY USING SOCIAL MEDIA DATA
}

\author{
Kunal Dilip CHANDIRAMANI* \\ Vellore Institute of Technology, Chennai (School of Computer Science Engineering), India, e-mail: kunal.kc.chandiramani@gmail.com \\ Nachimuthu MAHESWARI \\ Vellore Institute of Technology, Chennai (School of Computer Science Engineering), India, e-mail: maheswari.n@ vit.ac.in \\ Manickam SIVAGAMI \\ Vellore Institute of Technology, Chennai (School of Computer Science Engineering), India, e-mail: msivagami@ vit.ac.in
}

\begin{abstract}
Citation: Chandiramani, K.D., Maheswari, N., \& Sivagami, M., (2021). INSIGHTS OF GENDER BASED TOURISTS PREFERENCES BY CONSTRUCTING TRAVEL DIARY USING SOCIAL MEDIA DATA. GeoJournal of Tourism and Geosites, 38(4), 1098-1106. https://doi.org/10.30892/gtg.38415-749
\end{abstract}

\begin{abstract}
Insights into traveller's behavior are important for the Tourism Authority of Thailand to draw up plans and make decisions to manage and promote their capital city (Bangkok) as a tourism hub. Therefore, the objective of this paper is to obtain a comprehensive understanding of traveller's behavior in Bangkok. To achieve this, we used a variety of methods such as activity, temporal, and spatial analysis to identify visitor patterns in Bangkok by utilizing a relatively new data gathering technique to extract social media check-in data. The findings include comprehensive statistics about traveller's behavioral patterns at these spots that have practical implications in various city management applications.
\end{abstract}

Key words: Tourism, Travel Diary, Bangkok Metropolitan Administration, Tourism Authority of Thailand, Destination Management, Traveller Activities, Foursquare, Twitter

$$
* \quad * \quad * \quad * \quad * \quad *
$$

\section{INTRODUCTION}

All over the globe, tourism has become the most important service sector activity and a multi-billion - dollar industry over the years. Tourism is known as an engine of economic growth and progress; it contributes to a large amount of money in the economic development of any country (Statista, 2015). The role of the tourism industry in providing opportunities for jobs and generating national income have been well accepted worldwide. Many countries have described tourism activity as an essential component to job generation, inequality reduction, poverty alleviation and sustainable human growth (Vethirajan and Nagavalli, 2014; Ohlan and Ramphul, 2017). Therefore, understanding visitor behavior is an important task for tourism management organizations in promoting tourism activity and expenditure in destination countries. For many countries in Asia Pacific regions (e.g. Thailand, Malaysia and Vietnam), their capital cities are often promoted as a tourism destination to attract international visitors (McDowall et al., 2010; Wadeecharoen et al., 2018). These cities are often central hubs to link it to other destinations due to the developed transportation system, with high concentration of governmental management, businesses, manufacturing and financial centers. Overall, the capital cities in many countries play a very important role in improving that country as a tourist destination spot. Various studies have been conducted generally on analyzing the visitor's behavior in Thailand (McDowall et al., 2010). For a country like Thailand, its capital city (Bangkok) plays a vital role in the tourism industry, as Bangkok is the top revenue generating province in Thailand with a total revenue of 499,393 million baht (TAT NewsRoom, 2019). Furthermore, Bangkok was also identified as the "Best City" in Asia on 11 February 2020 by readers of Destin Asian and 'Best Destination Asia and the Pacific' at the 28th Irish Travel Awards Gala Dinner in Dublin, Ireland(TAT NewsRoom, 2019; TAT NewsRoom, 2020). Therefore, understanding visitor behavior and activity of Bangkok is not only beneficial to Thailand tourism industry, but also other neighbouring countries due to its role as a travel hub in the region (Vu et al., 2018; Vu et al., 2018).

Aiming to support Bangkok Metropolitan Administration (BMA) and Tourism Authority of Thailand (TAT) in better satisfying the needs of their visitors, this paper aims to conduct a comprehensive analysis of visitor activities in Bangkok, Thailand. Existing studies have shown that traditional approaches based on survey and question are inefficient in capturing traveller behaviors at a large and comprehensive level (Breen et al., 2001, Valori et al., 2012), therefore we propose to utilize big data from social media platform (e.g. Foursquare) to carry out the study, which was proven to be reliable in capturing traveler behavior in urban context (Salas-Olmedo et al., 2018). Foursquare is one of the popular location- based social media platforms for venue check-ins (Humeres et al., 2014). Data from this application contains not only the exact geographical information to pinpoint the user's location, but also provides information about the user's activities such as visited venue, venue types, and exact local time at the multiple destinations. We first collected a large-scale venue check

\footnotetext{
* Corresponding author
} 
data set, comprising 29300 check-ins made by 2655 travelers at 25153 unique locations in Bangkok. Exploratory analysis approaches that incorporate data on location, time, and activity, are performed to provide comprehensive insights into visitor's activities. The findings have potential to support tourism management organizations in Asia Pacific regions, especially Thailand, to better develop and promote their capital cities as attractive destinations to international visitors.

The rest of this paper is organized as follows. Section 2 provides a literature review of relevant works and highlights of research gaps. Section 3 describes the approach to data collection and exploratory analysis. Section 4 presents the results and discusses the finding of this study. The final section concludes the paper and offers future research directions.

\section{LITERATURE REVIEW}

\section{Thailand Tourism Industry}

The Thai tourism destination has a long history, although the modern industry may be assumed to have been in operation since the 1960s when the government formed the Tourism Authority of Thailand (TAT), to promote the country (Seaton at. al 2000). Afterwards, arrivals increased, and the country was by the 1980s one of South-East Asia's most popular destinations. The number of incoming visitors continuously grew and in 2010 amounted to 16 million (UNWTO 2013).

As reported by the World Travel \& Tourism Council (2015), the tourism industry is Thailand's main economic engine. In 2014, it contributed directly to $1,037,3$ billion baht of national GDP, roughly $8.6 \%$ of domestic GDP (Thailand's of Tourism and Sport, 2015). This data shows that in Thailand, international tourists have no faith in the political climate.

\section{Traveller's Activity Studies in Thailand}

The rapid growth in inbound tourism in Thailand has driven Thai tourism to become the second largest domestic industry market in recent decades (Liu et al., 2018). It is suspected that inbound tourism and the wellness tourism industry in Thailand have the ability to expand further (Liu et al., 2018; Tanyatanaboon and Brennan, 2016). Economic distress, however, has lately been higher than ever. Moreover, surprisingly, foreign tourists visiting some countries in Asia and Thailand are always attracted to the low prices of wellness tourism goods, not cultures, strong behavioural intent, and destination loyalty (Han et al., 2017; Hashemi et al., 2015).

Therefore, several scholars in the latest literature on tourism and customer behaviour have found the factors affecting such decision/compliance to support the tourism industry in Thailand, taking into consideration the critique of traveller analysis, advice decisions and behaviour (Byun and Jang, 2019; Eom and Han, 2019; Han and Hyun, 2017; Hudson et al., 2015; Hwang et al., 2019). Such studies are of special significance in the preparation of travellers for post-buying decisions about the consistency and characteristics of a commodity (Han and Hyun, 2017), the brand love (Roberts, 2006; Oliver, 2010; Hudson et al., 2015) and the obtained values (Hwang and Hyun, 2017).

\section{Social Media Platforms as Data Sources}

Web 2.0 apps that include user-generated contexts such as text, photographs and videos (Obar et al., 2015) are social media. With the large amount of data available, social media can offer insights on tourism activities, perceptions and grievances that are invaluable and traditionally difficult to obtain (Claster et al., 2015).

Tourism researchers have recently turned to social media as an alternative source of data for tourism. Casado-Díaz et al., (2021), incorporated three new drivers for analyzing visitors' expenditure patterns for the management of destinations. Claster et al., (2015) examined Twitter reviews to help us appreciate medical tourism 's capacity and inspiration in support of the medical services industry. In heritage hotels, Yoo and Lee (2015) analyzed Facebook messages for visitor actions and interpretation. Sinclair et al., (2020) investigated a methodology to estimate social media visitors' home locations at various spatial scales and apply it to the entire network of national parks in Germany. Users can exchange messages at a particular location at a certain time with the check-in feature on mobile social media. 'Check-in' is a famous way to show people's interest in a place or site (Versichele et al., 2014). Check-in functions for tracking are known as an effective way of developing long-term customer relations (Kessler et al., 2012).

\section{METHODS AND MATERIALS}

This section presents our approach to collect the venue check-in data to capture travel information of visitors in Bangkok, Thailand. Foursquare is used as our data source because of its effectiveness in recording traveller behaviours similar to the real-world situation. Foursquare allows users to make real check-ins by awarding incentive points for check-ins when users actually reside in or close selected places (Patil et al., 2012). The problem with the processing of data from Foursquare is that its platforms do not have functions for the direct detection of users and corresponding check-ins. However, these data can be viewed from another social media site, Twitter, as Foursquare enables users to connect and merge their other social media accounts together. If a check-in is made using a Foursquare application called Swarm, the device automatically sends a tweet to their related Twitter account so that users' friends on Twitter can also access their check-ins. Therefore, it is possible for users to collect foursquare check-in data via Twitter using its Application Programming Interface (API).

\section{Data Collection}

Firstly, the Streaming function twitter API was deployed to collect check-in tweets in the Bangkok area for a few months. The tweets are extracted using a unique feature where a user can extract tweets posted on a specific geographic area by using a bounding box by specifying four coordinate variables referenced as Xmax, Xmin, Ymax and Ymin. The tweets are initially saved and stored as records in the following format:

\{User_Id, User_location, User_language, tweets_id, date, time, day, GPS Coordinates\} 
Among the stored records the User_Id is a unique identification number which is different for every user on the foursquare app. The date-time attribute is the exact date and time when the check-in was made in the universal time zone. Secondly, we extracted the user's timeline of the identified visitors. A feature of the Twitter API, named getUserTimeLine, was used but due to the limitation of Twitter's public API, the function displays only up to 3,200 latest tweets to a given user. If the total number of tweets a user posts is less than 3,200, then the entire collection of tweets will be displayed. One major problem when extracting the user timeline of a particular user is that the twitter API extracts all the tweets posted by the users but we only need tweets that were posted by the user in Bangkok using the foursquare swarm check-in application. To solve this problem, we have applied a filter using the keyword "foursquare" and for every tweet we filtered if the user's location is within the city premises by using a bounding box. The collected dataset contains check-ins over a wide range of years, beginning in 2001 and ending in 2019. The number of check-ins is described in detail in Table 1.

\section{Data Pre-processing}

The major data pre-processing steps we have taken on the collected data are as follows:

- removed all the rows having null values

- removed special characters from the venue name and venue type attribute values.

- translated the venue name attributes from other languages like Chinese and Thai to English.

- Finally, we converted the string data extracted from the tweets into date-time format.

The final stage before the analysis is combining all the constructed travel diaries into a single file, so that it can be used for various types of analysis.

\begin{tabular}{|l|c|c|}
\hline & $\begin{array}{c}\text { Number } \\
\text { of Visitors }\end{array}$ & $\begin{array}{c}\text { Number of } \\
\text { check-ins }\end{array}$ \\
\hline Male & 2122 & 180214 \\
\hline Female & 533 & 112786 \\
\hline Total & 2655 & 293000 \\
\hline
\end{tabular}

Table 1. Summary of the

foursquare (Data source:

https://www.swarmapp.com/)

\section{Methods}

We have used various libraries and graph charts in this paper to analyse the behaviours of different types of tourists. For each analysis we have used different methods which are as follows:

- Activity preference analysis: we have produced a bar chart that summarizes the activity preferences of male and female visitors. Moreover, we have also conducted a z-test over the number of check-ins made by male and female tourists to better understand the behaviour of male and female tourists in each activity category.

- Temporal analysis: We used the matplotlib Python module to display the heap map diagram and identify the number of check-ins that occurred at various time intervals, which a heat map tells you in a graphical format that is easy to grasp and draw conclusions from.

- Regional Analysis: we have categorized the data into three categories which are relevant to this analysis Food Spots which consists of Food and Nightlife spot activity categories, Shopping Spots - which consists of Shop and Service activity category and Entertainment Spots - which consists of Art and Entertainment and Outdoor \& Recreation activity categories, the other activity categories are discarded since they may not have difference in check-in patterns based on the region. In order to perform the analysis, we first count the number of check-ins made every hour in the foursquare dataset for each class in various areas throughout the week. Furthermore, we sum up all check-ins made between Monday and Friday as weekdays and other check-ins as weekends to provide tourism managers with deeper, more gradual insights. We then standardize the numbers by its region's greatest value in that particular category, allowing us to compare the patterns discovered in other regions. For demonstrative purposes, we only included the top five most popular Bangkok neighborhoods from our dataset.

- Loyalty Analysis: In this analysis, the data was again divided into three categories: Food Spots, Shopping Spots, and Entertainment Spots. On the categorised data, we have calculated various performance metrics which can help tourism managers to understand the loyalty of a venue like Total number of check-ins at each venue $\mathrm{i}$ (TCi), Total number of unique users that checked-in to venue i (TUi) and Average user check-in frequency at Venue i (AUFi).

- Spatial Analysis: We have used google earth pro application and highlighted features such as city borders, districts and district borders, Shanghai Metro lines, the road structure and various icons to represent different venue types on a map of Bangkok, Thailand.

\section{RESULTS AND ANALYSIS}

In this section of the paper, we have used the constructed travel diaries to make various types of analysis and find out their corresponding outcomes, which may help the tourism managers to make important decisions when recommending tourist spots in Bangkok, Thailand. Travel diaries are very descriptive about the behavior of the visitors., Thailand. The Day, Date and Time features in the travel diary helps the managers to know the places where visitors like to visit during the daytime and the nighttime. Furthermore, the Venue_Name, Venue_Type features can help the tourism managers to know about the popular places of visitor's interest. The various types of analyses that we have performed on the constructed travel diaries are as follows:

\section{Activity Preference Analysis}

The nature of travel between different groups of visitors differs. To evaluate the travel actions of various traveler groups, we have demonstrated the ability of travel diaries built from check-in data to assess the preference of male and female groups. One major barrier for summarizing the activity preferences of these groups is that there are several types of locations in the data collected. In order to solve this issue, we have categorized each venue into ten separate categories of operation, which are described in Table 2. We have explored the disparity between the actions of male and female communities. The bar chart of activity preferences between male and female visitor groups is shown in Figure 1.

Some of the findings observed from Figure 1 and Table 3 are described as follows: 
- The z-test score in the Travel \& Transportation activity category is 21.33 , indicating that male visitors are more likely than female tourists to take public transportation. However, the z-test result in the Shop and Service activity category is -8.81 , indicating that female visitors are more drawn to shopping malls and other departmental and clothing stores than male visitors.

- The z-test result in the Food category is -31.62 , demonstrating that female visitors have a higher percentage of checkins than male visitors. Male visitors, on the other side, had a greater percentage of check-ins in the nightlife spots category, with a z-test value of 3.71. This contrast in behavior demonstrates that male tourists prefer to eat in bars, lounges, pubs, and so on, but female visitors prefer to eat at restaurants and cafes.

- The z-test result in the professional and other locations category is 9.29 , indicating that male tourists prefer to visit more cultural places such as temples, spiritual centers, and convention centers. While female visitors prefer traveling to art galleries, museums, theaters, and multiplexes, the Art and Entertainment category has a z-test score of -10.08.

- The z-test score in the Events category is -7.46 , whereas male visitors had a much larger proportion of outdoor \& recreational activity check-ins, with a z-test score of 20.92. This differential in behavior suggests that male visitors prefer to spend their time at beaches, sporting facilities, and golf courses, whilst female visitors prefer to spend their time at malls, concerts, and roadways.

Table 2. Activity Categories

\begin{tabular}{|c|l|l|}
\hline Sr. No & Activity Category & Famous Locations \\
\hline 1. & Travel \& Transportation (T\&T) & Airport, Train, bus, metro stations. Hotels. \\
\hline 2. & Art \& Entertainment(A\&E) & $\begin{array}{l}\text { Art Gallery, Art Museum, Cultural Centre, Concert Hall, Stadium, Movie Theatre, Theme Park, } \\
\text { Zoo, Multiplex }\end{array}$ \\
\hline 3. & Events (Et) & Market, conference, festival, Road \\
\hline 4. & Food (Fd) & $\begin{array}{l}\text { American, Asian, Italian, Japanese, Mexican Restaurants. Coffee shop, BBQ Joint restaurant, } \\
\text { Noodle house, Dessert Shop }\end{array}$ \\
\hline 5. & Shop \& Service (S\&S) & $\begin{array}{l}\text { Shopping Mall, Airport Service, Convenience, Departmental, Accessories, Clothing, Electronic } \\
\text { Stores. Massage parlour }\end{array}$ \\
\hline 6. & $\begin{array}{l}\text { Professional \& other places } \\
\text { (P\&OP) }\end{array}$ & $\begin{array}{l}\text { Animal shelter, auditorium, ballroom, building, community, convention, cultural center, spiritual } \\
\text { center factory. }\end{array}$ \\
\hline 7. & Nightlife Spot (NS) & Lounge, Bar, night market, nightclub. \\
\hline 8. & Outdoors \& Recreation (O\&R) & Athletic sports, Golf Course, beach. \\
\hline 9. & College \& University (C\&U) & College academic building, college bookstore, college library, college lab, student center \\
\hline 10. & Residence (Rd) & Assisted living, home, housing development, residential building, trailer park \\
\hline
\end{tabular}

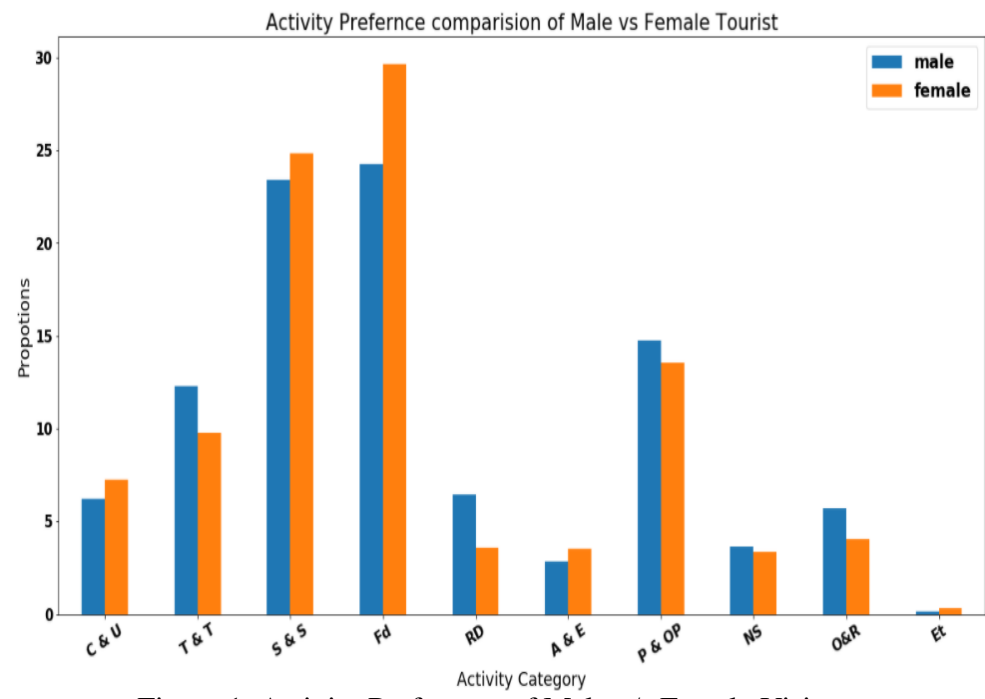

Figure 1. Activity Preference of Male v/s Female Visitors
Table 3. The Z-test Score obtained for the activity preference of Male vs Female visitor

\begin{tabular}{|c|c|c|c|c|}
\hline $\begin{array}{c}\text { Activity } \\
\text { Category }\end{array}$ & $\begin{array}{c}\text { Proportion } \\
\text { of Male }\end{array}$ & $\begin{array}{c}\text { Proportion } \\
\text { of Female }\end{array}$ & Difference & $\begin{array}{c}\mathrm{Z} \\
\text { Score }\end{array}$ \\
\hline $\begin{array}{c}\text { College and } \\
\text { University }\end{array}$ & 6.21 & 7.22 & 1.01 & -10.58 \\
\hline $\begin{array}{c}\text { Travel \& } \\
\text { Transportation }\end{array}$ & 12.27 & 9.76 & 2.51 & 21.33 \\
\hline $\begin{array}{c}\text { Art \& } \\
\text { Entertainment }\end{array}$ & 2.84 & 3.52 & 0.68 & -10.08 \\
\hline Events & 0.17 & 0.32 & 0.15 & -7.46 \\
\hline Food & 24.28 & 29.64 & 5.36 & -31.62 \\
\hline Shop \& Service & 23.42 & 24.85 & 1.43 & -8.81 \\
\hline $\begin{array}{c}\text { Professional \& } \\
\text { other places }\end{array}$ & 14.77 & 13.55 & 1.22 & 9.29 \\
\hline Nightlife Spot & 3.64 & 3.38 & 0.26 & 3.71 \\
\hline $\begin{array}{c}\text { Outdoors \& } \\
\text { Recreation }\end{array}$ & 5.71 & 4.03 & 1.68 & 20.92 \\
\hline Residence & 6.44 & 3.57 & 2.87 & 35.74 \\
\hline
\end{tabular}

\section{Temporal Analysis}

It's very challenging to manage restaurants, cafes, malls, dessert shops and managing the crowd flow of visitors during peak hours. In order to eliminate this problem, we are going to figure out the trend of the number of customers that these popular spots may expect at various points of time each day. The temporal analysis of these spots offers managers insights into the time periods and days when there will be more crowds, which will allow them to schedule staff and purchase ingredients accordingly. Discussing the temporal analysis, Figure 2(a) shows strong presence of visitors on Friday and Saturday night at nightlife spots. While Figure 2(b) and Figure 2(c) indicate that visitors tend to prefer restaurants throughout the week but again Friday, Saturday and Sunday are the busiest days of the week for restaurants and shopping malls. These findings are consistent with the fact that Saturday and Sunday being a holiday for many offices, people prefer to visit tourist locations during these days. On the other hand, if we dive deeper to see the time intervals when more check-ins are made at these tourist spots, restaurants and shopping malls have a higher number of visitors between time intervals $12: 00 \mathrm{pm}$ to $9: 00 \mathrm{pm}$. While the check-ins made at nightlife spots are more after 9:00 $\mathrm{pm}$ and at the temples are more during the morning time starting from 9:00 am. 


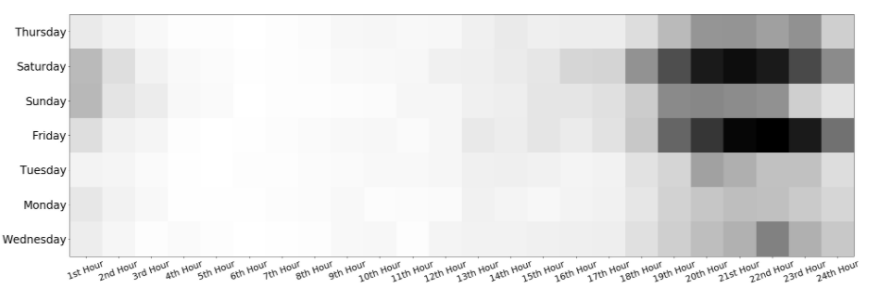

(a)Temporal Analysis of Nightlife Spots

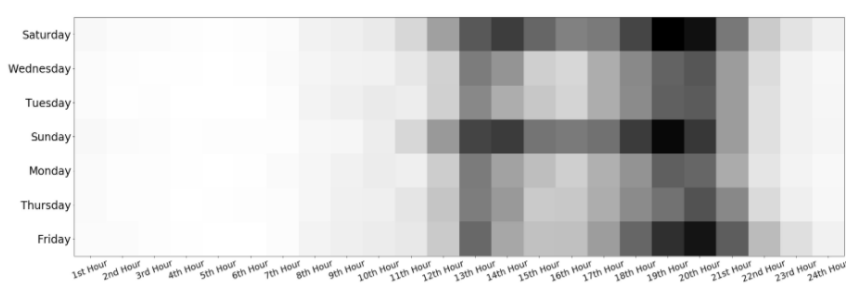

(b) Temporal Analysis of Restaurants

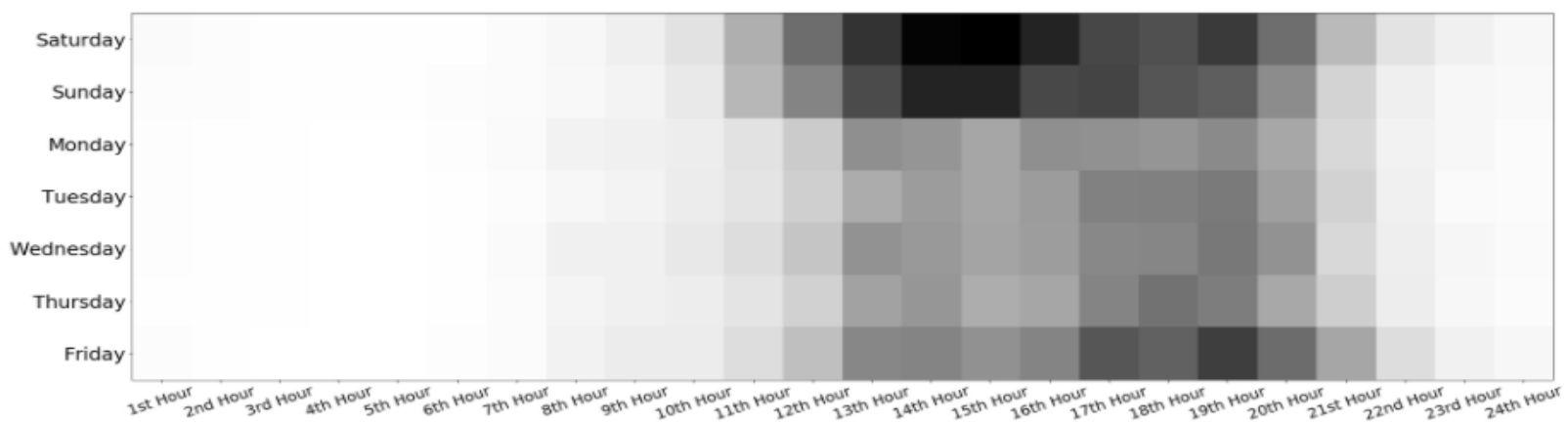

(c) Temporal Analysis of shopping malls

Figure 2. Comparison of Temporal Analysis at various tourist spots

\section{Regional Analysis}

In this subsection of the paper, we shift our attention to regional analysis by targeting various regions of Bangkok on weekends and weekdays. The time periods when check-ins are performed in various regions of Bangkok may provide valuable inputs to the tourism managers to help them understand tourism even better than before.

Discussing the weekday pattern, Figure 3 indicated that all the regions of Bangkok have almost similar temporal patterns in all the classes with peaks occurring at similar times despite differences in venues in various regions. At the Shopping spots on weekdays most of the check-ins made by the visitors are between 12:00pm to 7:00pm, after 7:00 we can see a drastic decrease in the number of check-ins. At Food spots on weekdays, two peaks occurring for all the regions in Figure 3(b) one is at $12 \mathrm{pm}$ which is when generally people like to have lunch and one is during 7:00 pm which is when people like to have dinner, but if we take a deeper look at Figure 3(b) we can see a exception in Hua Mak region of Thailand where the second peak of dinner occurs between 5:00 pm and 6:00 pm instead of 7:00 pm.

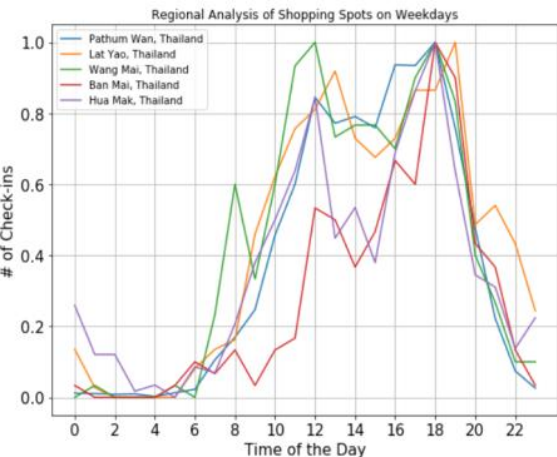

(a) Shopping Spots

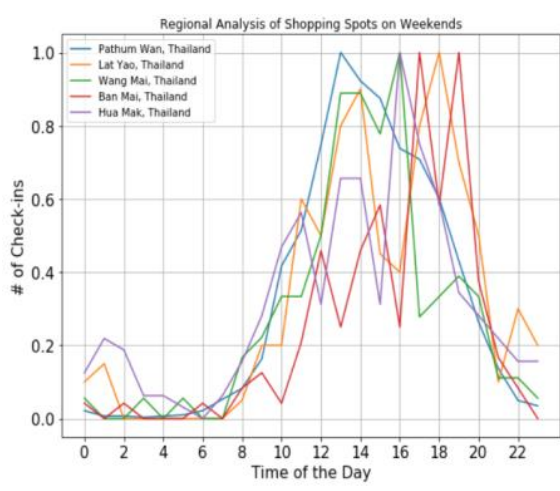

(a) Shopping Spots

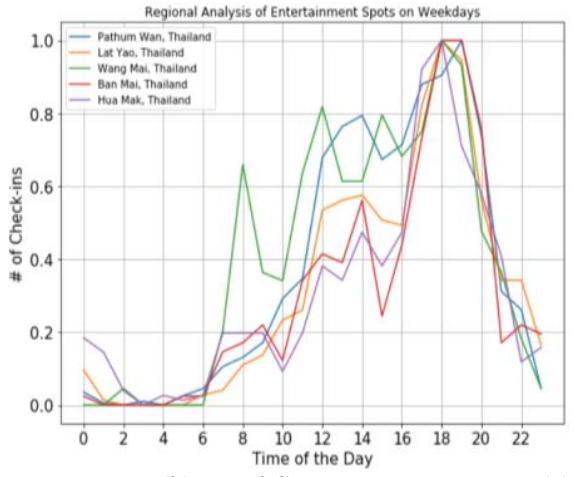

(b) Food Spots

Figure 3. Regional Analysis on Weekdays

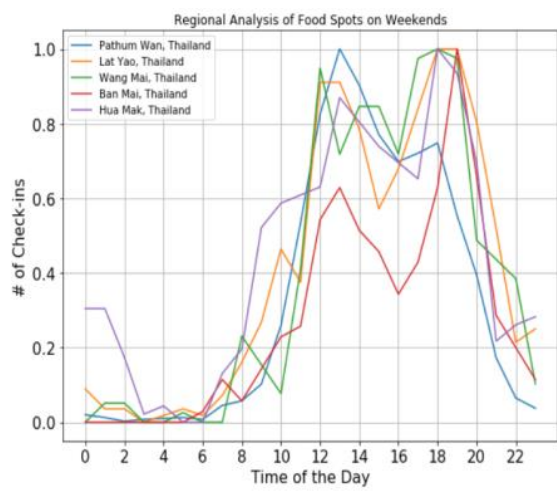

(b) Food Spots

(c) Entertainment Spots

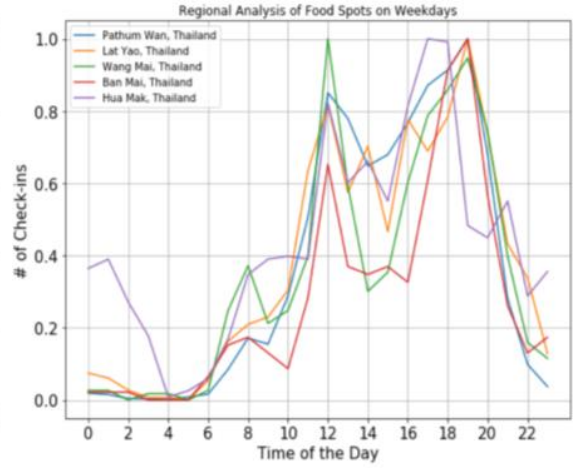

(c) Entertainment Spots

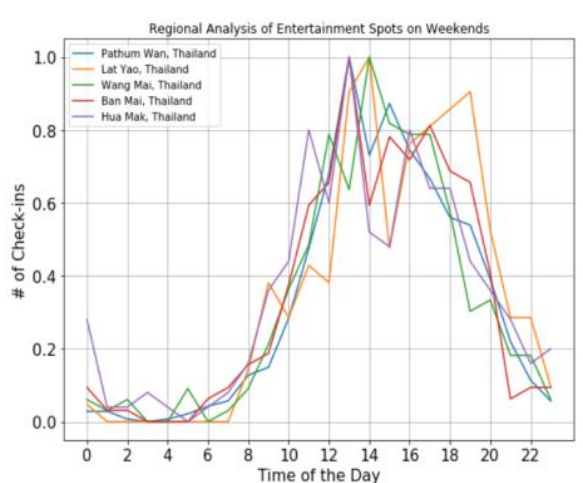

Figure 4. Regional Analysis on Weekends 
This may be the case because restaurants close early in that region or maybe because people in that area are likely to have dinner earlier than those in other regions. Also, one more exception occurs between 12:00 am and 2:00 am in the Hua Mak region, where the peak in the graph indicates that it has a greater number of nightlife venues than other regions. Finally, in the Entertainment spots on weekdays, Figure 3(c), all of the regions have almost identical temporal patterns, with the peak occurring between 6:00 and 7:00 pm, though if we look closely, the temporal pattern of the Wang Mai region is a little different in the morning time implying that this region may have entertainment spots that can be visited in the morning. Discussing the weekend pattern of various regions of Bangkok, Figure 4 indicated that all the regions except Pathum Wan region have similar temporal patterns with peaks and minimums happening at similar hours of the day. At Shopping spots on weekends, Figure 4(a) all the regions have similar temporal patterns except the Pathum Wan region where peak occurs at 1:00 pm and after which there is a decrease in the number of check-ins on the other hand, other regions have peak occurring at nearby hours of the day for Lat Yao region peak occurs at 6:00 pm, for Wang Mai and Hua Mak region peak occurs at 4:00 pm and finally for Ban Mai peaks occurs at 5:00 pm and 7:00 pm. Also, if we look closely at Figure 4 (a), the graph shows that there are a lot of check-ins happening in Thailand's Hua Mak region at night, which could imply night events in the Hua Mak region on weekends. At Food spots on weekends, Figure 4(b) all the regions have similar temporal patterns with peaks happening at twice, once around 1:00 pm which is likely the lunch time and the second time around 7:00 pm which is likely the dinner time. The only significant difference we observe is in the temporal patterns of Pathum Wan where peak occurs only once and in the temporal patterns of Hua Mak where there are high numbers of check-ins between 12:00 am to 2:00 pm as well.

Now let us turn our attention to discuss the difference in temporal patterns of each class on weekdays and weekends. At the shopping spots, we observe that the temporal patterns of visitors shopping are quite similar on weekdays and weekends with peaks occurring between 12:00 pm and 6:00 pm and minimum occurring during the morning time. At the Food spots, we observe that on weekdays the lunch time check-in mostly occurs only at 12:00 pm although on weekends the lunch time check-ins occur at 12:00 pm and goes on with high check-ins till 2:00pm, but the dinner habits of all the visitors are almost similar for weekends and weekdays. At the Entertainment spots, we observe that the peaks at the entertainment spots on weekdays happens generally between 6:00 pm and 7:00 pm because of people on the other hand on weekend the peak at the entertainment spots occurs between 12:00 pm to 2:00 pm, this disparity in check-ins suggests that people don't get free time in the morning during weekdays, so they visit entertainment spots during the night time while on weekends they visit these venues during the afternoon time.

\section{Loyalty Analysis}

In this subsection of the paper, we have analyzed the overall loyalty of various venues and categories by finding out the total number of check-ins and total number of users who have checked-in to these locations. To perform this analysis, we have calculated the following measures from our dataset for each of the classes:

(a) Total number of check-ins at each venue i (TCi)

(b) Total number of unique users that checked-in to venue $\mathrm{i}(\mathrm{TUi})$ and

(c) Average user check-in frequency at Venue i (AUFi). We calculate AUFi as:

$$
\mathrm{AUFi}=(\mathrm{TCi} / \mathrm{TUi})
$$

\begin{tabular}{|c|c|c|c|}
\hline & Shopping Spots & Food Spots & Entertainment Spots \\
\hline Max of TC & 4229 & 4254.0 & 645 \\
\hline Min of TC & 1.0 & 1.0 & 1.0 \\
\hline Mean of TC & 19.06 & 8.83 & 16.28 \\
\hline Max of TU & 948 & 648.0 & 287 \\
\hline Min of TU & 1.0 & 1.0 & 1.0 \\
\hline Mean of TU & 7.51 & 5.16 & 8.65 \\
\hline Median of TU & 1.0 & 1.0 & 1.0 \\
\hline Stand. Dev of TU & 37.14 & 19.72 & 26.22 \\
\hline Max of AUF & 4.46 & 6.65 & 2.24 \\
\hline Min of AUF & 1.0 & 1.0 & 1.0 \\
\hline Mean of AUF & 2.53 & 1.71 & 1.88 \\
\hline
\end{tabular}

Table 4. Statistics of TC, TU AND AUF in each category

The third metric, the average check-in frequency of the customer, can also be deemed as the loyalty to a location. Therefore, AUF of venues in shopping, food and entertainment spots can help the owners to understand their clients, as well as enable the customers to evaluate comparable retailers which offer similar types of service. Take for instance, in our Foursquare dataset, mean customer loyalty is about 3, and Starbucks coffee House has loyalty of around 5. On this basis, the owner will see that there are many returning customers at his venue, and he can give those returning customers special offers for their support. In the meanwhile, if a customer is searching for a decent coffee house in that region, they can correlate the overall average customer loyalty number and the loyalty number of Starbucks coffee houses. Since the coffee house has loyalty numbers above the average of other comparable venues, then Starbucks coffee house is higher than the average. However, for the above instance to be true, we have assumed that all the check-ins are honest and are from the real customers. The statistics of TC, TU and AUF of shopping, food and entertainment spots are given in Table 4. Furthermore, we also list the top 5 venue names with the highest number of check-ins and their AUF values in each of the categories in Table 5. This table will help the customers know about the likelihood of people visiting a particular place more than once, higher the AUF value higher will be the likelihood that people return to that place after visiting once.

\section{Spatial Analysis}

We analyze the spatial patterns in this section by visualizing the positioning of groups of check-in venues and the density of total check-ins using google earth pro application on a map of Bangkok, Thailand.

From Figure 5, we can observe that Bangkok being one of the major cities of Thailand has been well planned by the officials, where most of the famous locations are located either towards the center or near the Bangkok metro railways, which is represented using black line in the above map. However, we can observe that Government Buildings, Gas 
Stations and Hospitals are relatively dispersed over the map. Furthermore, to dive a little more deeper we have conducted spatial-temporal analysis by plotting density distribution of check-ins over the map of Bangkok for four different months of the year, two of them being the months consisting highest number of check-ins (April and March) while the other months consisting least number of check-ins (June and July).

\begin{tabular}{|c|c|c|c|c|c|}
\hline \multicolumn{2}{|l|}{ Shopping Spots } & \multicolumn{2}{|c|}{ Food Spots } & \multicolumn{2}{|l|}{ Entertainment Spots } \\
\hline Venue Name & AUF & Venue Name & AUF & Venue Name & AUF \\
\hline Siam Paragon & 4.46 & Starbucks & 6.56 & Paragon Cineplex & 2.24 \\
\hline CentralPlaza Lardprao & 4.17 & Bon Chon Chicken & 2.20 & SF Cinema City & 2.42 \\
\hline Central Orld & 3.16 & Bar B Q Plaza & 2.74 & \begin{tabular}{|l|l|l} 
SFX & Cinema \\
\end{tabular} & 2.92 \\
\hline CentralPlaza Grand Rama 9 & 3.74 & MK & 2.47 & Major Cineplex Ratchayothin & 2.63 \\
\hline Terminal21 & 3.01 & After You & 2.30 & Bangkok Art and Culture Centre (BACC) & 1.41 \\
\hline
\end{tabular}

Table 5. List of Venues with highest number of check-ins and their AUF values

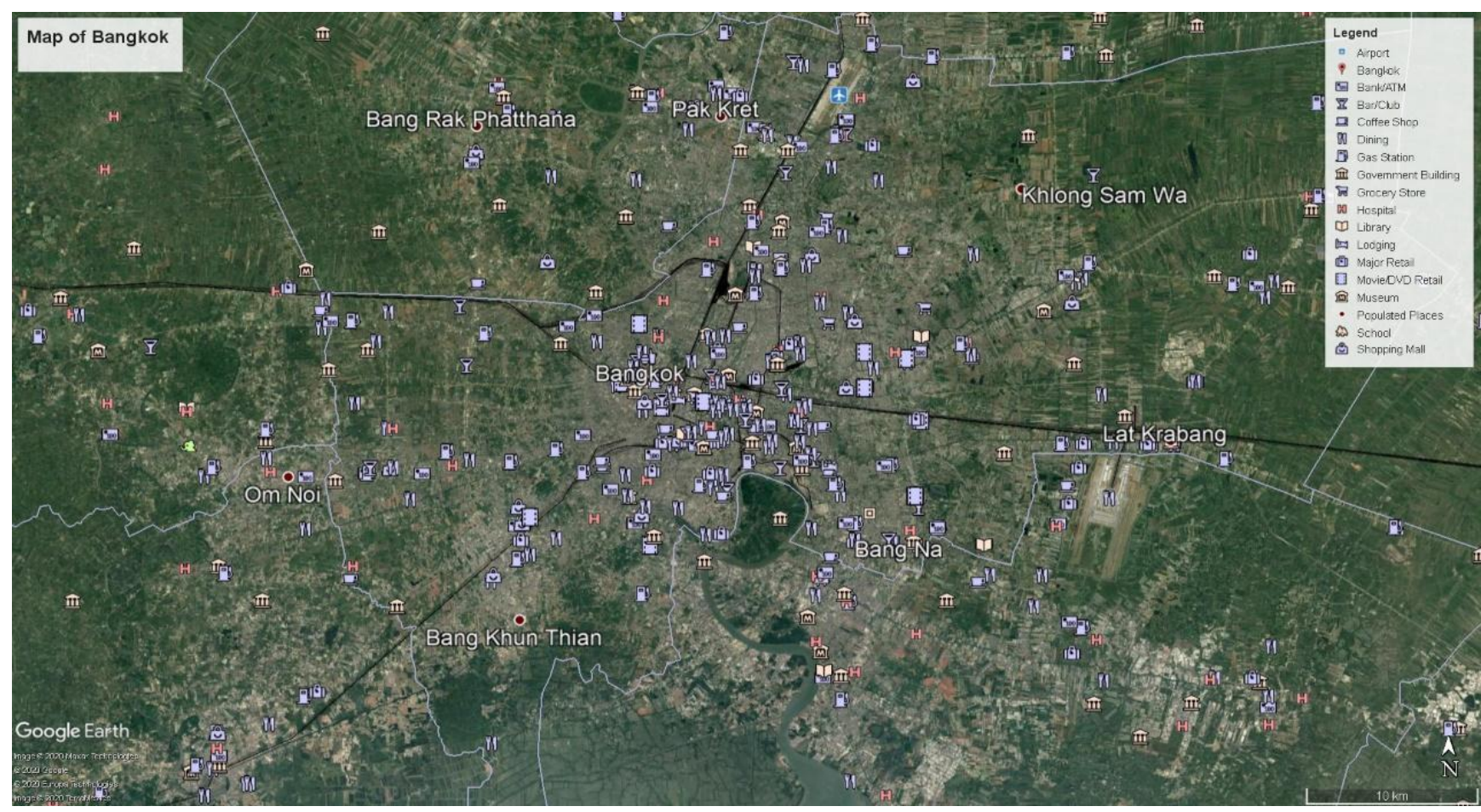

Figure 5. Spatial Analysis of famous locations on the map of Bangkok (Satellite Image Source: https://www.google.com/intl/en_in/earth/)

Figure 6 represents the density distribution of check-ins over the map of Bangkok in four different months. Red color represents high density of check-ins in that area and yellow color represents average density of check-ins, while it eventually dissolves into the base color of the map for areas with no check-in densities. The first two figures (Figure 6 a) plots the density distribution of months that have maximum number of check-ins and the last two figures (Figure 6 b) plots the density distribution of check-ins for months that have least number of check-ins.

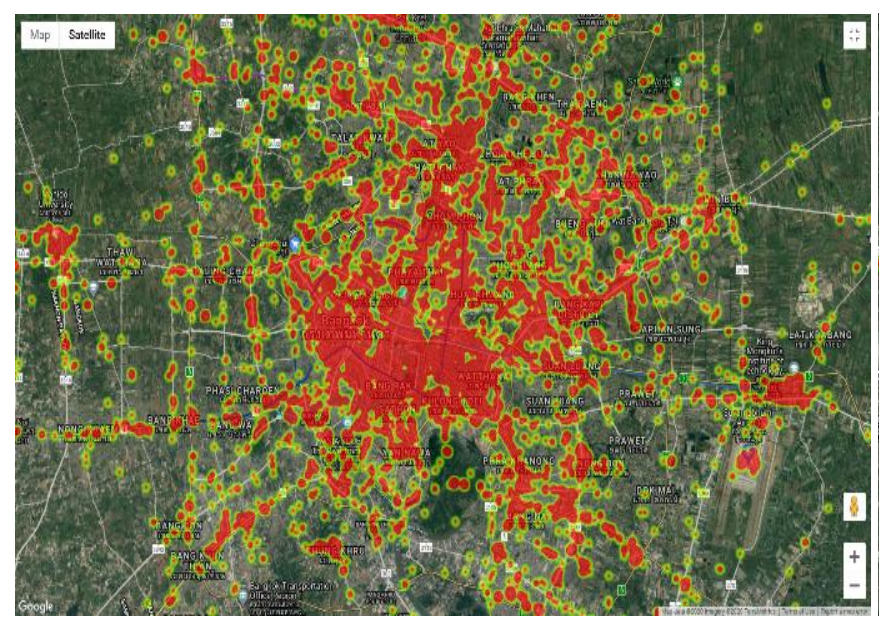

(a) Month of March \& April

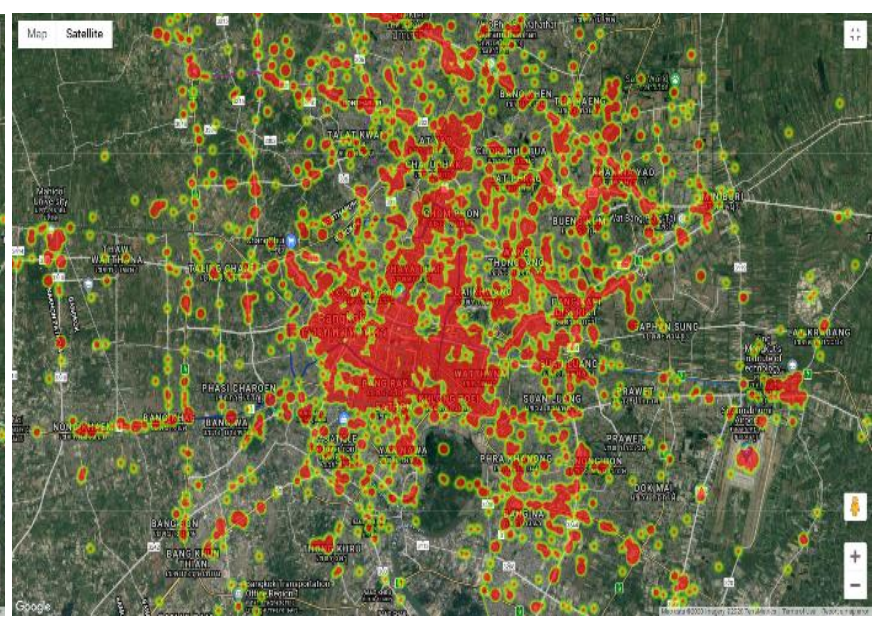

(b) Month of June \& July

Figure.6 Comparison of monthly check-in density distribution 
From Figure 6 it can be observed that although the months of June and July have a smaller number of check-ins the center of map remains denser even during those months, whereas the overall check-in distribution covers a larger area in the months of March and April. Moreover, it is important to note that the central area of Bangkok is the commercial center, and hence, this area has more facilities in almost every aspect.

Nevertheless, the city of Bangkok is highly developed and modern with lots of facilities spread across the whole area of Bangkok, therefore check-in clusters can be seen in various places across the city.

\section{CONCLUSION AND FUTURE WORK}

In this paper, we have demonstrated the capability of travel diaries in providing detailed insights into activities and preferences in Bangkok. We also used a system for collecting details on Foursquare and gathering travel information without having to touch visitors directly. From the findings in the analysis section, travel organizations can make appropriate recommendations for male and female visitors to visit these types of venues to satisfy their needs. Male visitors may be provided with the details about public transit to facilitate them in regular usage of public transit. This discovery will help alleviate traffic congestion in Bangkok for many visitors. Female visitors' tourism marketing materials may also include public transport information to encourage visitors to Bangkok and help them easily travel to various places. In order to meet their travel needs, the preferred mode of transport for female visitors can be investigated.

Moreover, this paper includes comprehensive statistics about the days and hours at most visited places, using the Heat Map tool to clearly view the activity-analysis cycle. We also expanded this analysis by comparing weekdays and weekend seasonal trends of the topmost populated regions around Bangkok. Both the temporal and regional analysis were conducted on different types of venues in various categories of activities. This research will allow managers to prescribe exact timetables for tourists to visit different destinations in order to prevent overcrowded locations, which could have positive effects on visitors' satisfaction. We have also used constructed travel diaries to examine geo-spatial data to discover different trends on the Bangkok map. This research was carried out in order to gain clear observations of locations and check-ins via mapping. The findings have shown that while the number of check-ins is comparatively lower for a few months, the centre of the map remains a denser region even in those months, suggesting the availability of more popular places in the area. Besides this, we have also built a way to discover location's loyalty to the users that can provide tourism managers with a deeper insight into the most famous and loyal venues in the various categories that tourists want to visit in Bangkok. All these analyses can be carried out in other locations in the near future in order to provide more detailed information. Moreover, the analysis can be extended on other different categories of tourist groups like Asian and Western, the analysis could also include visitor opinions such as tips on venues.

\section{ACKNOWLEDGEMENT}

It is our pleasure to express our sincere gratitude to Dr. Quan Vu and Dr. Gang Li of Deakin University, Australia for their constant guidance, motivation and understanding. Our relationship with them is not limited to academia alone, but it is a wonderful chance for us to collaborate with an intellectual and a specialist in the area of computer science. We would also like to express our gratitude to the Vellore Institute of Technology for providing a working atmosphere and for their inspiration.

\section{REFERENCES}

Breen, H., Bull, A., \& Walo, M. (2001). A comparison of survey methods to estimate visitor expenditure at a local event. Tourism Management, 22(5), 473-479. https://doi.org/10.1016/S0261-5177(01)00005-X

Byun, J., \& Jang, S. (2019). Can signaling impact customer satisfaction and behavioral intentions in times of service failure?: Evidence from open versus closed kitchen restaurants. Journal of Hospitality Marketing \& Management, 28(7), 785-806. https://doi.org/10.1080/19368623.2019.1567432

Casado-Díaz, A.B., Navarro-Ruiz, S., Nicolau, J.L., \& Ivars-Baidal, J. (2021). Expanding our understanding of cruise visitors' expenditure at destinations: The role of spatial patterns, onshore visit choice and cruise category. Tourism Management, 83, 104199. https://doi.org/10.1016/j.tourman.2020.104199

Claster, W., Ghotbi, N., \& Shanmuganathan, S. (2015). Gathering medical tourism information through algorithmic text analysis of tweets. In Current issues and emerging trends in medical tourism, 173-188, IGI Global. https://doi.org/10.4018/978-1-4666-8574-1

Eom, T., \& Han, H. (2019). Community-based tourism (TourDure) experience program: A theoretical approach. Journal of Travel \& Tourism Marketing, 36(8), 956-968. https://doi.org/10.1080/10548408.2019.1665611

Han, H., \& Hyun, S.S. (2017). Impact of hotel-restaurant image and quality of physical-environment, service, and food on satisfaction and intention. International Journal of Hospitality Management, 63, 82-92. https://doi.org/10.1016/j.ijhm.2017.03.006

Han, H., Kiatkawsin, K., Kim, W., \& Lee, S. (2017). Investigating customer loyalty formation for wellness spa: Individualism vs. collectivism. International Journal of Hospitality Management, 67, 11-23. https://doi.org/10.1016/j.ijhm.2017.07.007

Hashemi, S.M., Jusoh, J., Kiumarsi, S., \& Mohammadi, S. (2015). Influence factors of spa and wellness tourism on revisit intention: The mediating role of international tourist motivation and tourist satisfaction. International Journal of Research, 3(7), 1-11. https://doi.org/10.29121/granthaalayah.v3.i7.2015.2976

Hudson, S., Roth, M.S., Madden, T.J., \& Hudson, R. (2015). The effects of social media on emotions, brand relationship quality, and word of mouth: An empirical study of music festival attendees. Tourism management, 47, 68-76. https://doi.org/10.1016/j.tourman.2014.09.001

Humeres, M.F.J. (2014). Power Centrality as a relational measure of urban hierarchy: testing the splintering urbanism theory with social media data from Santiago de Chile

Hwang, J., Cho, S.B., \& Kim, W. (2019). Consequences of psychological benefits of using eco-friendly services in the context of drone food delivery services. Journal of Travel \& Tourism Marketing, 36(7), 835-846. https://doi.org/10.1080/10548408.2019.1586619 
Kessler, S. (2010). The future of the hotel industry and social media. available at: Mashable. com, http://mashable. com/2010/10/18/hotel-industry-social-medial.(Accessed 10 July 2016).

Liu, Y., Li, Y., \& Parkpian, P. (2018). Inbound tourism in Thailand: Market form and scale differentiation in ASEAN source countries. Tourism Management, 64, 22-36. https://doi.org/10.1016/j.tourman.2017.07.016

McDowall, S., \& Ma, E. (2010). An analysis of tourists' evaluation of Bangkok's performance, their satisfaction, and destination loyalty: Comparing international versus domestic Thai tourists. Journal of Quality Assurance in Hospitality \& Tourism, 11(4), $260-282$. https://doi.org/10.1080/1528008X.2010.504181

Obar, J.A., \& Wildman, S.S. (2015). Social media definition and the governance challenge-an introduction to the special issue. Obar, JA and Wildman, S.(2015). Social media definition and the governance challenge: An introduction to the special issue. Telecommunications policy, 39(9), 745-750. http://dx.doi.org/10.2139/ssrn.2663153

Ohlan, R. (2017). The relationship between tourism, financial development and economic growth in India. Future Business Journal, 3(1), 9-22. https://doi.org/10.1016/j.fbj.2017.01.003

Oliver, R.L. (2010). Satisfaction: A behavioral perspective on the consumer. ME Sharpe. Inc., New York.

Patil, S., Norcie, G., Kapadia, A., \& Lee, A. (2012). "Check out where I am!" location-sharing motivations, preferences, and practices. In CHI'12 Extended Abstracts on Human Factors in Computing Systems (pp. 1997-2002). https://doi.org/10.1145/2212776.2223742

Roberts, K. (2006). The lovemarks effect: Winning in the consumer revolution. Mountaineers books.

Salas-Olmedo, M.H., Moya-Gómez, B., García-Palomares, J.C., \& Gutiérrez, J. (2018). Tourists' digital footprint in cities: Comparing Big Data sources. Tourism Management, 66, 13-25. https://doi.org/10.1016/j.tourman.2017.11.001

Seaton, A. (2000). Thailand's tourism. In J. Jafari (Ed.), The encyclopaedia of tourism, (pp. 610-612). London: Routledge.

Sinclair, M., Mayer, M., Woltering, M., \& Ghermandi, A. (2020). Using social media to estimate visitor provenance and patterns of recreation in Germany's national parks. Journal of Environmental Management, 263, 110418. https://doi.org/10.1016/j.jenvman.2020.110418

Tanyatanaboon, B., \& Brennan, M. (2016). Health \& wellness market reports Bangkok [PDF document].

Valori, L., Picciolo, F., Allansdottir, A., \& Garlaschelli, D. (2012). Reconciling long-term cultural diversity and short-term collective social behavior. Proceedings of the National Academy of Sciences, 109(4), 1068-1073. https://doi.org/10.1073/pnas.1109514109

Versichele, M., De Groote, L., Bouuaert, M.C., Neutens, T., Moerman, I., \& Van de Weghe, N. (2014). Pattern mining in tourist attraction visits through association rule learning on Bluetooth tracking data: A case study of Ghent, Belgium. Tourism Management, 44, 67-81. https://doi.org/10.1016/j.tourman.2014.02.009

Vethirajan, C., \& Nagavalli, S. (2014). Trends and Growth of the Tourism Sector in India-A Research Perspective. Indian Journal of Research, 3(11), 9-11.

Vu, H.Q., Li, G., Law, R., \& Ye, B.H. (2015). Exploring the travel behaviors of inbound tourists to Hong Kong using geotagged photos. Tourism Management, 46, 222-232. https://doi.org/10.1016/j.tourman.2014.07.003

Vu, H.Q., Li, G., Law, R., \& Zhang, Y. (2018). Travel diaries analysis by sequential rule mining. Journal of travel research, 57(3), 399413. https://doi.org/10.1177/0047287517692446

Wadeecharoen, W., Lertnaisat, R., \& Pongbugnor, O. (2018). International tourists confident toward Thailand destination satisfaction: A case of Singapore Malaysia and Lao PDR tourist. In 2018 5th International Conference on Business and Industrial Research (ICBIR) (pp. 445-450). IEEE. https://doi.org/10.1109/ICBIR.2018.8391238

Yoo, K. H., \& Lee, W. (2015). Use of Facebook in the US heritage accommodations sector: An exploratory study. Journal of Heritage Tourism, 10(2), 191-201.

*** Ministry of Tourism and Sport, Thailand. (2015). Retrieved 14 July 2020, from http://www.mots.go.th/mots_en57/main.php?filename=index.

*** Statista (2015). Direct and Total Contribution of Travel and Tourism to the Global Economy from 2006 to 2017, Trillion U.S. Dollars, Statista.

*** TAT Newsroom. (2020). Tourism revenue grows in Thailand's emerging destinations in Jan-June 2019 - TAT Newsroom. Retrieved 17 September 2020. https://www.tatnews.org/2019/09/tourism-revenue-grows-in-thailands-emerging-destinations-in-jan-june-2019

*** TAT Newsroom (2020). Amazing Thailand wins Best Asia-Pacific Destination at Irish Travel Trade Awards 2019 - TAT Newsroom. Retrieved 11 May 2020, https://www.tatnews.org/2019/12/amazing-thailand-wins-best-asia-pacific-destination-at-irishtravel-trade-awards-2019

*** TAT Newsroom. (2020). Bangkok named Best City 2020 by DestinAsian's Readers - TAT Newsroom. https://www.tatnews. org/2020/02/bangkok-named-best-city-2020-by-destinasians-readers/

*** UNWTO Annual Report 2013 | UNWTO. Unwto. org. (2020). Retrieved 20 August 2020. https://www.unwto.org/archive/ global/publication/unwto-annual-report-2013

*** World Travel \& Tourism Council (WTTC) | Travel \& Tourism Representative Council. Wttc.org. (2020). Retrieved 20 October 2020, from http://www.wttc.org/.

Article history: Received: 23.05.2021 Revised: 02.09.2021 Accepted: 04.10.2021 Available online: 28.10.2021 